\title{
Optimization of Environmentally Benign Polymers Based on Thymine and Polyvinyl Sulfonate Using Plackett-Burman Design and Surface Response
}

\author{
Julieta Ledesma, ${ }^{1}$ Santiago A. Bortolato, ${ }^{2}$ Carlos E. Boschetti, ${ }^{1}$ and Débora M. Martino ${ }^{2,3}$ \\ ${ }^{1}$ Área Tecnología Química, Facultad de Ciencias Bioquímicas y Farmacéuticas, Universidad Nacional de Rosario, \\ Suipacha 531, S2002LRK Rosario, Argentina \\ ${ }^{2}$ Instituto de Desarrollo Tecnológico para la Industria Química (INTEC), Güemes 3450, S3000GLN Santa Fe, Argentina \\ ${ }^{3}$ Facultad de Humanidades y Ciencias, Universidad Nacional del Litoral, Paraje El Pozo, S3080HOF Santa Fe, Argentina
}

Correspondence should be addressed to Santiago A. Bortolato; sbortolato@intec.unl.edu.ar

Received 15 February 2013; Accepted 24 April 2013

Academic Editor: Sofia Trakhtenberg

Copyright (C) 2013 Julieta Ledesma et al. This is an open access article distributed under the Creative Commons Attribution License, which permits unrestricted use, distribution, and reproduction in any medium, provided the original work is properly cited.

\begin{abstract}
Traditional approaches to the development of integrated circuits involve the use and/or manufacture of toxic materials that have a potential environmental impact. An extensive research has been done to design environmentally benign synthetic polymers containing nucleic acid bases, which can be used to enhance the photoresistor technologies. Water soluble, environmentally benign photopolymers of 1-(4-vinylbenzyl) thymine (VBT) and vinylphenyl sufonate (VPS) undergo a photodimerization reaction when exposed to low levels of ultraviolet irradiation leading to an immobilization of the copolymer on a variety of substrates. PlackettBurman design (PBD) and central composite design (CCD) were applied to identify the significant factors influencing the polymer crosslinking and dye adsorption processes, which are relevant in the fabrication of copolymer films for potential photoresist use. The PBD results assigned a maximum absorption signal of 0.67 , while optimal conditions obtained in this experiment following the CCD method predictions provided a response of $0.83 \pm 0.03$, being a solid foundation for further use of this methodology in the production of potential photoresistors. The $\mathrm{pH}$ effect was relevant for low concentrations but not significant for higher concentrations. To the best of our knowledge, this was the first report applying statistical experimental designs to optimize the crosslinking of thymine-based polymers.
\end{abstract}

\section{Introduction}

The success of semiconductor technologies in recent decades has been based primarily on what is called the photolithography technique, often used to make integrated circuits [1]. Photolithography is the process by which optical methods are used to transfer the circuit patterns from master images (masks) to substrates, typically silicon wafers. The traditional approaches to the development of integrated circuits involve obtaining small pieces at low cost, without considering the toxicity of the materials used and/or manufactured, and their potential environmental impact. During the last decades, extensive research has been done to design environmentally benign synthetic polymers containing nucleic acid bases, which can be used to enhance the photoresistor technologies
[2-5]. The need for an inexpensive, stable, and versatile system which incorporates thymine moieties in the polymer backbone leads to the design of a new synthetic monomer, the 1-(4-vinylbenzyl) thymine (VBT) [6], that has the ability to photocrosslink upon irradiation with short-wavelength ultraviolet (UV) component of sunlight [6-8]. This process was bioinspired on the photodimerization of thymine, one of the DNA bases, both in vivo and in vitro under irradiation with ultraviolet light, which disrupts the helical structure of DNA $[4,5]$.

The versatility of VBT makes it an attractive research platform, since the balance between photoreactivity, solubility, and noncovalent interactions can be fine-tuned for a variety of applications. Since the VBT homopolymer is water insoluble due to strong intermolecular interactions, 
the copolymerization of VBT with charged functional groups can improve its solubility. Among them, substituted styrenes either cationic such as vinylbenzyl triethylammonium chloride (VBA) and N-butyl-N,N-dimethyl-(4-vinylbenzyl)ammonium chloride (BDMQ), or anionic such as vinylphenyl sufonate (VPS), allow for obtaining a fully waterprocessable photoresist, eliminating the need of toxic solvents $[9,10]$. The resulting photopolymers of VBT and VPS or VBA are water soluble, environmentally benign, and undergo a photodimerization reaction of the pendant thymine units when exposed to low levels of ultraviolet irradiation. This process leads to an immobilization of the copolymer on a variety of substrates in response to irradiation and allows the removal of unexposed regions by aqueous wash (photoresist), having potential applications in a variety of fields [9-19]. Trakhtenberg et al. introduced the photoresistive capacity of VBT-VPS copolymers and demonstrated that they can be used as a viable template for enzymatic synthesis of conductive polyaniline, allowing for surface photopatterning with a conductive polymer under mild conditions [15]. The same copolymer was also used in photoresist applications $[9,20]$. In those works, the authors immobilized the copolymers to form thin films on polyethylene terephthalate (PET) substrate and demonstrated that the process is potentially useful for the advancement of photoresistors [20].

In photolithography technique, in order to create the patterns, the wafers are coated with a photosensitive material called photoresist, which changes its solubility upon exposure to light through an appropriate mask of UV opaque material. This allows the selective irradiation of only the desired areas of the photoresist-coated wafer, thus transferring the pattern from the mask onto the wafer. After being exposed to light the photoresist-coated wafer goes into a developing solution that selectively removes the resist layer from unexposed areas, resulting in a wafer with the semiconductor surface partially protected by the resist [21]. In subsequent steps, the unprotected areas are modified, for example, by chemical etching, while protected areas remain intact. Finally the remaining photoresist is stripped off the wafer, which now features the pattern identical to the one on the mask. This process can be repeated several times, using different masks [1]. Figure 1 schematically presents the photolithography process.

Taking into account that the photoimmobilized copolymer film is very thin $(<1 \mu \mathrm{m})$ and translucent, the immobilized copolymer coatings are typically visualized by dipping the resulting patterned films into a solution of an oppositely charged dye. The dye chosen for VPS was methylene blue (MB) given that it has a net positive charge that favors the physisorption process on the polymer, as it was shown [9]. The dye selectively adsorbs on the charges of the photocrosslinked copolymer, providing clear contrast from the unreacted regions. The amount of adsorbed dye can be monitored by UV-VIS spectroscopy, measuring the absorbance at $610 \mathrm{~nm}$ ( $\mathrm{MB}$ absorbance maximum), and therefore a correspondence among the measured absorbance and the amount of immobilized charged groups on the substrate surface can be made [9].

The technological applications of these polymers were seen earlier than the necessary basic studies, which could

\begin{abstract}
Step 1: clean substrate
Step 2: coat substrate with photoresist

Step 3: expose to UV light through mask
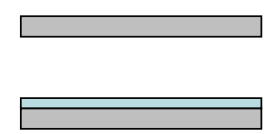

$h v$

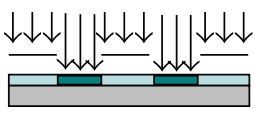

Step 4: develop unexposed resist

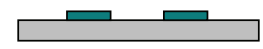

Step 5: transfer pattern to substrate via etching

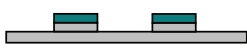

Step 6: strip photoresist

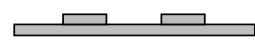

FIGURE 1: Description of photolitography process.
\end{abstract}

help to understand their behavior and improve their service. Therefore, more studies need to be done in order to optimize the proposed photocrosslinking method due to the large amount of variables that have effect on the processing and development of these copolymers. To begin with, thymine is a compound having acid-base behavior with a $\mathrm{pKa} \sim 9$, and it has been demonstrated that at $\mathrm{pH}$ greater than $\mathrm{pKa}$ thymine exists mostly in its anionic form, in an equilibrium between two tautomers (ratio 1:1), one of which cannot crosslink [22]. It was found experimentally that increasing the proportion of VPS in its VBT-VPS copolymer, the $\mathrm{pH}$ of the solution increases to values close to 11 , which could produce a significant reduction in the efficiency of the crosslinking process. However, the efficiency and reproducibility of the method used to prepare VBT-VPS coatings may depend on other factors, including the coating thickness and the copolymer composition [20]. Although the works cited before $[9,20]$ are very helpful to screen important factors influencing film preparation, they are insufficient to establish a general rule for manufacturing certain photoresist polymers with reliable properties. In general, it is difficult to obtain the comprehensive effects of some factors through a reasonable number of experiments. Solving this problem in a rational way involves performing an experimental design [23]. This procedure can be summarized in three stages: (1) identification of factors that can influence the results of the experiments, (2) use of statistical analysis to separate and evaluate the effects of the various factors involved "screening phase"; and (3) with the significant factors, get the best response possible for the developed experiment "response surface phase" [23]. The primordial difference between the classical one-variableat-a-time method and the experimental design is that, in the latter case, the values of all the factors are varied in each experiment in a programmed and rational way. Some of the studied factors will probably have no influence on the experiment, and only few will act upon the response; therefore, the essential factors can be detected while keeping the number of trials to a minimum.

Plackett-Burman design (PBD) is a method that can inspect up to $N-1$ factors in $N$ experiments and is commonly 
used in the screening phase of a wide range of processes [2426]. It has been proven to be an efficient way of evaluating a large number of variables and identifying the significant ones from a statistical point of view [23-26]. Therefore, in this study, PBD method was applied to identify the significant factors influencing the polymer crosslinking and dye adsorption processes that are relevant in the fabrication of copolymer films for potential photoresist use. The effects of seven controllable factors on the process performances were studied. Selected operational variables were $\mathrm{pH}$, concentration, dyeing time, solution stability, coating thickness, comonomer ratios, and film drying time. The absorbance corresponding to the methylene blue dye at $610 \mathrm{~nm}$, as an indication of VBT-VPS crosslinking efficiency, was chosen as the response value of the PBD experiments.

Once the various factors affecting the results of an experiment have been identified through PBD, a separate method is needed to determine the combination of factor levels, which will provide the optimum response. First it is necessary to carefully define what is meant by "optimum response" in a given experimental procedure; in our case, the optimum outcome of the experiment would be the maximum signal-to-noise ratio in the absorbance measurements. With that in mind, the response surface methodology (RSM) is an efficient experimental tool with which the optimal conditions of a multivariable system may be determined. This strategy includes a large number of statistical techniques [23, 27], in particular the Central Composite Design (CCD) which was used to explore the relationships between several descriptive variables and one response variable.

In this work, the optimization of the main factors affecting the polymer photocrosslinking and subsequent dye adsortion processes was carried out by means of an experimental design. The goal of the present research is to quantitatively assess the effects of numerous variables over the photocrosslinking process and to propose the best experimental conditions for the improvement of photoresistors based on VBT and VPS copolymers in a rational way and at low cost of experiments.

\section{Materials and Methods}

2.1. Materials. All reagents were purchased in the purest available form and were used as received. Sodium hydroxide, isopropanol, and acetone were purchased from Cicarelli (Buenos Aires, Argentina). 4-Vinylbenzyl chloride, 2,2'azobis-2-methylpropionitrile (AIBN), 2,6-di-tert-butyl-4methylphenol, thymine, and methylene blue (MB) were purchased from Sigma-Aldrich (SA) (Buenos Aires, Argentina). VBT was synthesized from thymine and vinylbenzyl chloride as described previously [6]. VPS salt was purchased from Fluka (Buenos Aires, Argentina). Based on ${ }^{1} \mathrm{H}$ NMR spectra and melting point results, the monomeric products were deemed pure enough for the synthesis of the polymers.

Hydrophilic polyethylenterephthalate film (PET-X4C1, Dupont) was used as substrate without previous treatment. Coatings were done using wire-round milled coating rods purchased from RDS Corp. (Webster, NY, USA). Irradiations

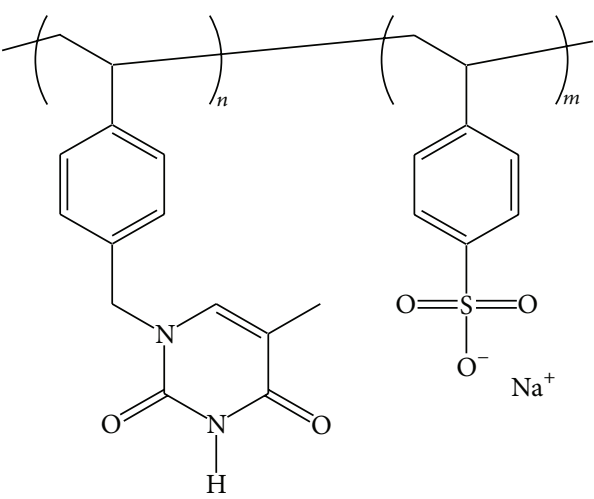

SCHEME 1: Structure of VBT-VPS copolymers $(n=1$ and $m=1,4$, $8,16$, or 32$)$

were performed using a UV hand lamp (Spectroline UL, Model ENF 260c, Spectronics Corporation Westbury, NY, USA). Absorbance measurements were taken with Spectronic Genesys spectrophotometer (Thermo Electron Corporation, USA), UV-VIS spectra were collected on Jasco V-630 UV-VIS spectrophotometer (Jasco Inc., USA), and ${ }^{1} \mathrm{H}$ NMR spectra were taken on Bruker $300 \mathrm{MHz}$ NMR spectrometer.

2.2. Copolymer Synthesis and Characterization. To produce water-soluble polymers, VBT was copolymerized in a free radical process with the anionic monomer, VPS. The ratio of VBT: VPS comonomers influences the behavior of the VBT polymeric system and varies depending on the application. Therefore, $\mathrm{VBT}_{n}: \mathrm{VPS}_{m}$ have been synthesized with $n=1$ and $m=1,4,8,16,32$.

VBT: VPS 1:1 copolymer: to a $300 \mathrm{~mL}, 3$-neck, roundbottomed flask containing $250 \mathrm{~mL}$ of a $50 \%(\mathrm{v} / \mathrm{v})$ aqueous solution of isopropanol, VBT $(11.9 \mathrm{~g}, 0.049 \mathrm{~mol})$ and VPS $(10.1 \mathrm{~g}, 0.049 \mathrm{~mol})$ were added. The solution was heated to $65^{\circ} \mathrm{C}$ while stirring and $0.22 \mathrm{~g}$ of AIBN was added. Stirring was continued for $16 \mathrm{~h}$ while the temperature was maintained at $65^{\circ} \mathrm{C}$. The reaction mixture was cooled to room temperature and rotary evaporated to concentrate to $125 \mathrm{~mL}$ in vacuo. Adding the aqueous solution to $1 \mathrm{~L}$ of cold acetone precipitated the polymer. Subsequently, the white solid precipitate was filtered and then dried under vacuum for 2 days. To verify the absence of unreacted monomers, the precipitated polymer was analyzed by ${ }^{1} \mathrm{H}$ NMR spectroscopy and the typical vinyl group signal at chemical shifts between 5 and $6 \mathrm{ppm}$ was not observed in the spectra. Additionally, elemental analysis was used to confirm copolymer ratios [9]. Scheme 1 presents the structure of the VBT-VPS copolymers.

VBT:VPS 1:4, 1:8, 1:16, and 1:32 copolymers were synthesized with identical procedures only varying the corresponding ratios of starting monomers.

2.3. Coating Preparation and Film Irradiation. Aqueous solutions of each VBT: VPS $m(m=1,4,8,16,32)$ copolymers were distributed homogeneously on PET film using either a no. 3 or no. 6 wire-round milled coating rod. The films were dried at room temperature for one hour and in 
TABLE 1: Experimental variables used in the Plackett-Burman design.

\begin{tabular}{|c|c|c|c|c|c|}
\hline Variable & Type & Units & Symbol & Low level & High level \\
\hline $\mathrm{pH}$ & Numerical & $\mathrm{a}$ & A & 6 & 12 \\
\hline Concentration & Numerical & $\% \mathrm{gL}^{-1}$ & $\mathrm{~B}$ & 2 & 10 \\
\hline Dyeing time & Numerical & Sec & $\mathrm{C}$ & 30 & 120 \\
\hline Stability & Numerical & Day & $\mathrm{D}$ & 1 & 30 \\
\hline \multirow[t]{2}{*}{ Coating thickness } & Numerical & $\mu \mathrm{m}$ & $\mathrm{E}$ & 6.8 & 13.6 \\
\hline & & & & Level one & Level two \\
\hline Drying film $^{\mathrm{b}}$ & Categorical & $\mathrm{a}$ & $\mathrm{F}$ & Yes & No \\
\hline Comonomer ratio $^{c}$ & Categorical & a & G & $1: 1$ & $1: 4$ \\
\hline
\end{tabular}

${ }^{a}$ Not applicable. ${ }^{b}$ Drying as explained in Section $2.3 .{ }^{c} 1: 1=$ VBT $: \mathrm{VPS}_{1}, 1: 4=\mathrm{VBT}: \mathrm{VPS}_{4}$.

TABLE 2: Twelve-trial PBD matrix for seven variables (A to G): experimental input values, and observed and predicted absorbance ${ }^{a}$.

\begin{tabular}{|c|c|c|c|c|c|c|c|c|c|}
\hline \multirow{2}{*}{ Run order } & \multicolumn{7}{|c|}{ Experimental values } & \multicolumn{2}{|c|}{ Absorbance $^{\mathrm{b}}$} \\
\hline & A & $\mathrm{B}$ & $\mathrm{C}$ & $\mathrm{D}$ & $\mathrm{E}$ & $\mathrm{F}$ & G & Observed & Predicted \\
\hline 1 & 12.0 & 2 & 30 & 1 & 13.6 & Yes & $1: 4$ & 0.18 & 0.17 \\
\hline 2 & 6.00 & 10 & 30 & 30 & 13.6 & No & $1: 4$ & 0.54 & 0.52 \\
\hline 3 & 12.0 & 10 & 120 & 1 & 13.6 & No & $1: 1$ & 0.58 & 0.61 \\
\hline 4 & 12.0 & 2 & 120 & 30 & 13.6 & Yes & $1: 4$ & 0.10 & 0.11 \\
\hline 5 & 12.0 & 2 & 30 & 30 & 6.8 & No & $1: 1$ & 0.44 & 0.37 \\
\hline 6 & 6.00 & 2 & 30 & 1 & 6.8 & Yes & $1: 1$ & 0.39 & 0.43 \\
\hline 7 & 6.00 & 10 & 30 & 30 & 13.6 & Yes & $1: 1$ & 0.67 & 0.70 \\
\hline 8 & 6.00 & 2 & 120 & 1 & 13.6 & No & $1: 1$ & 0.61 & 0.58 \\
\hline 9 & 6.00 & 2 & 120 & 30 & 6.8 & No & $1: 4$ & 0.15 & 0.19 \\
\hline 10 & 12.0 & 10 & 30 & 1 & 6.8 & No & $1: 4$ & 0.24 & 0.28 \\
\hline 11 & 6.00 & 10 & 120 & 1 & 6.8 & Yes & $1: 4$ & 0.36 & 0.29 \\
\hline 12 & 6.00 & 2 & 120 & 30 & 6.8 & No & $1: 4$ & 0.17 & 0.19 \\
\hline
\end{tabular}

${ }^{\mathrm{a}} \mathrm{A}-\mathrm{G}$ are symbols shown in Table $1{ }^{\mathrm{b}}$ Absorbance measured at $610 \mathrm{~nm}$.

a vacuum oven (at $80^{\circ} \mathrm{C} \sim 20$ torr) for another hour to give a uniform wet thickness of $6.8 \mu \mathrm{m}$ or $13.6 \mu \mathrm{m}$ according to the coating rod specifications [28]. Films were protected from the environmental light throughout the process.

All copolymer-coated films were irradiated with a UV hand lamp at $254 \mathrm{~nm}$ from a distance of $1 \mathrm{~cm}$ at different times (from 10 to 60 seconds) for the preliminary studies and one minute for the experimental design. This process leads to the immobilization of the polymer in response to the irradiation (photoresist material). The curing reaction due to radiation was achieved at room temperature; thus these coatings can be prepared on heat sensitive materials.

The samples were then immersed into an aqueous solution of $\mathrm{MB}$ dye $\left(1 \times 10^{-3} \mathrm{M}\right)$ for 30 or $120 \mathrm{~s}$. Next, they were dried by hot air or at room temperature and visually examined for uniform coloring. The photocrosslinking was monitored indirectly by UV-VIS spectroscopy measuring the efficiency of dye adsorption.

2.4. Plackett-Burman Design. Plackett-Burman design (PBD) [29] was used in the present study to screen the essential variables that significantly influence the photocrosslinking process. In this study, a 12-run PBD, including a replicated one to analyze the model lack of fit, was applied to evaluate seven factors: five numerical and two categorical. Each variable was examined at two levels, according to the guidelines of PBD [29]. Table 1 illustrates the seven variables and their corresponding levels (low/high for numerical variables and one/two for categorical variables) used in the experimental design. The values of the levels were set according to our preliminary experimental results.

The PBD and the response values of absorbance corresponding to $\mathrm{MB}$ dye adsorption on photocrosslinked copolymer, both the observed and predicted by the PBD model, are shown in Table 2.

2.5. Response Surface Methodology. The optimal levels of the significant factors and the interactions of these variables in a photocrosslinking process were analyzed by Central Composite Design (CCD). In this study, a two-factor, fivelevel CCD with 10 runs was employed. The tested variables ( $\mathrm{pH}$ and polymer concentration) were denoted as $X_{1}$ and $X_{2}$, respectively. The numerical variables were assessed at five different levels, combining factorial, axial, and central points, according to the guidelines of CCD [27]. The values for the three tested variables are shown in Table 3.

2.6. Statistical Analysis and Software. The analysis of variance (ANOVA) was conducted to determine the importance of the models and the regression coefficients, both in PBD and CCD assays. The statistical significance of the employed models, 
TABLE 3: Levels of the variables tested in the CCD.

\begin{tabular}{|c|c|c|c|c|c|c|c|}
\hline Variable & Type & Symbol & \multicolumn{2}{|c|}{ Factorial levels } & \multicolumn{2}{|c|}{ Axial levels } & Central level \\
\hline$\overline{\mathrm{pH}}$ & Numerical & $X_{1}$ & 7.50 & 10.50 & 6.00 & 12.00 & 9.00 \\
\hline Concentration & Numerical & $X_{2}$ & 4.00 & 8.00 & 2.00 & 10.00 & 6.00 \\
\hline
\end{tabular}

their terms, and their lack of fits were checked by Fisher's Ftest [30]. This test is used for comparing the model variance with the residual (error) variance: if the variances are close to the same value, their ratio will be close to unity, and it is less likely that any of the factors, terms, or lack of fits will have a significant effect on the response.

In $C C D$, the quality of the polynomial equation was judged from the determination coefficient $\left(R^{2}\right)$, the predicted $R^{2}$ (pred- $R^{2}$ ), which measures how good the model predicts a response value, the $R^{2}$ adjusted for the number of parameters in the model relative to the number of points in the design $\left(\operatorname{Adj}-R^{2}\right)$, which estimates the amount of variation around the mean explained by the model, and its statistical significances were checked also by Fisher's $F$-test [30]. The surface response and the contour plots of the predicted model responses were used to assess the interactive relationships between the significant variables.

Design-Expert software [27] was used for designing the experiments as well as for the regression and graphical analysis of the experimental data obtained.

\section{Results and Discussion}

3.1. Preliminary Step. The variables that could influence the polymer photocrosslinking and subsequent dye adsorption process were defined as follows. It was demonstrated that the irradiation time is positively related to the degree of photocrosslinking and how this relationship is modified when changing the VBT: VPS copolymer ratio up to a proportion $1: 16$ [9]. However, such analysis was carried out qualitatively, and therefore it is not possible to predict accurately the behavior of the photocrosslinking process.

Figure 2 shows the total intensity of $\mathrm{MB}$ absorption signal as function of irradiation time for polymer films at the same concentration (2\%), with different VBT to VPS ratios $(1: 1$ to $1: 32)$. It can clearly be observed that the greater the proportion of VPS to VBT, the larger the irradiation time required to immobilize the polymer on the substrate surface and the lower the amount of dye adsorbed on the polymer after saturation. In general, these results are in good agreement with previous reported data [9]. However, from the potential technological-utility point of view, it is clear that mixtures with higher proportion of VPS $(1: 8,1: 16$, and $1: 32)$ are not convenient since the sensitivity of the absorption signal is poor at 60 seconds compared with the VBT:VPS $(1: 1)$. Based on these preliminary results, the analysis of the experiments was completed only with the polymers of the lowest ratio of VPS $(1: 1$ and $1: 4)$.

On the other hand, it is reasonable that the dyeing time significantly influences the observed signal as this process favors the physisorption, although previous studies did not explain in detail the effect of this factor [9]. Therefore, dyeing time is defined as a potential influential variable in the process.

Experimentally it was found that the $\mathrm{pH}$ value of the $\mathrm{VBT}_{1}: \mathrm{VPS}_{32}$ solution increases to 11. Furthermore, the $\mathrm{pH}$ of the solution containing fewer amounts of VPS is around 6.5. On this basis, the $\mathrm{pH}$ influence on the photocrosslinking process was analyzed, since it can affect the acid-base behavior of thymine [22] and therefore reduce the efficiency of photocrosslinking process.

In addition, it was found experimentally that the $\mathrm{pH}$ of the solutions with greater VPS percentage $(1: 8$ to $1: 32)$ was modified over time, and after 30 days of preparation the $\mathrm{pH}$ stabilized in a value close to 6 . While the explanation for this phenomenon is not completely clear, the stability of the solutions was considered as a potential influential variable in the process.

It has been shown that the film thickness controls the crosslinking process, being more effective as the thickness reduces [31]. Therefore two coating thicknesses were compared to see how this variable could influence the process. Similarly, it is likely that increasing the polymer concentration in the solution influences the process. Previous works used $10 \%$ aqueous solution of VBT-VPS $[9,20]$. From an environmentally perspective, it seemed interesting to verify whether or not lower concentration values give good responses, as well.

Finally, it was reported that the retained water in the coated film could modify the process [31, 32]. Two alternative drying methods were compared to test the statistical significance of the drying method: (a) one hour at room temperature and (b) an additional hour in oven at $100^{\circ} \mathrm{C}$.

In summary the seven experimental variables used in the PBD are shown in Table 1.

3.2. Screening Step. The data listed in Table 2 indicates a wide variation in the absorption signal corresponding to methylene blue dye adsorbed on the photocrosslinked polymer, from 0.10 to 0.67 , in the 12 trials. This variation suggests that the optimization process is crucial for improving and controlling the dye adsorption after the photocrosslinking process. The analysis of the regression coefficients of the seven factors presented in Table 4 showed that factors B, C, and F had positive effects on dye adsortion, whereas factors A, D, E, and $G$ had negative effects.

A Model $F$ value of 13.12 (see Table 4 ) indicates that the model is significant; there is only a $1.28 \%$ chance that a "Model $F$ Value" this large could occur due to noise [30]. The variable with "Prob $>F$ " value lower than 0.0500 points out that model terms are significant, while values greater than 0.1000 indicate that the model terms are insignificant [30]. It was clear that variables $A, B, E$, and $G$ were the significant factors, while 


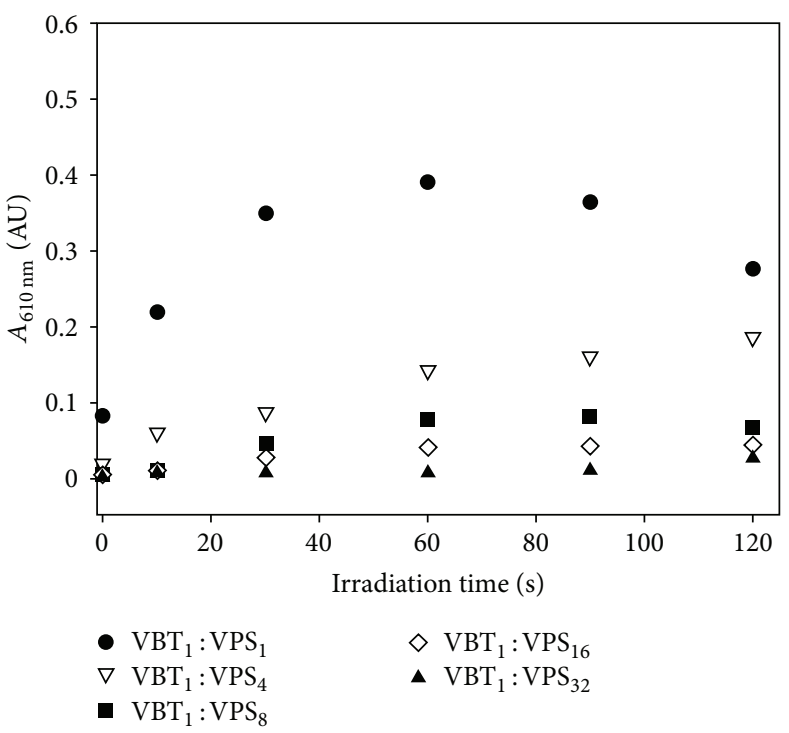

(a)

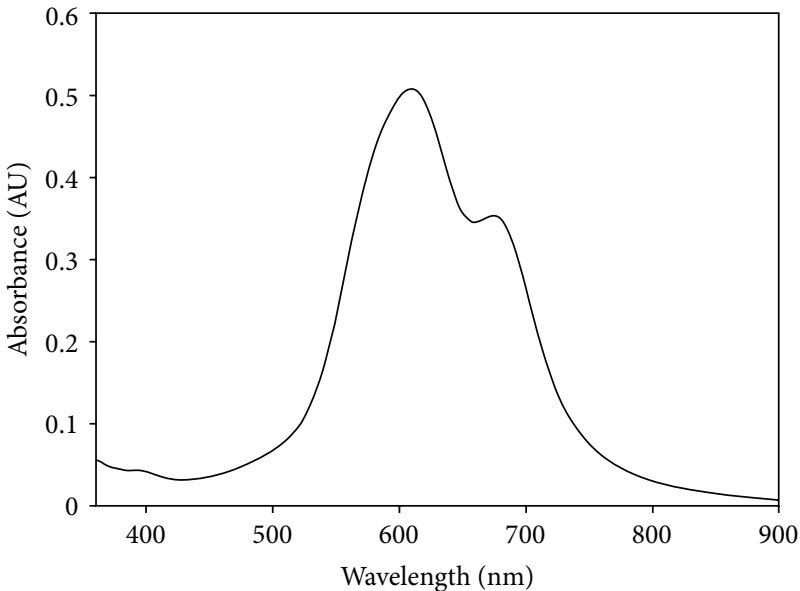

(b)

Figure 2: (a) Time evolution of MB absorption signal for polymer films at the same concentration (2\%), with different VBT to VPS ratios (1:1 to $1: 32$ ). (b) UV-VIS absorption spectra of polymer film of VBT: VPS ${ }_{1}$ at $2 \%$ and 60 seconds irradiation.

TABLE 4: Effects of the variables and statistical analysis of the PBD.

\begin{tabular}{|c|c|c|c|c|c|c|}
\hline Source & Coefficient estimate ${ }^{\mathrm{a}}$ & Sum of squares & $\mathrm{df}^{\mathrm{b}}$ & Mean square & $F$ value & $\begin{array}{c}P \text { value } \\
\text { Prob }>F\end{array}$ \\
\hline Model & & 0.4215968 & 7 & 0.06022811 & 13.1201459 & 0.0128 \\
\hline A & -0.0630 & 0.03967072 & 1 & 0.03967072 & 8.64190442 & 0.0424 \\
\hline B & 0.079 & 0.06239922 & 1 & 0.06239922 & 13.593102 & 0.0211 \\
\hline $\mathrm{C}$ & -0.02242 & 0.00503972 & 1 & 0.00503972 & 1.09785677 & 0.3539 \\
\hline $\mathrm{D}$ & -0.0058 & 0.00034116 & 1 & 0.00034116 & 0.07431762 & 0.7986 \\
\hline $\mathrm{E}$ & 0.0600 & 0.03602371 & 1 & 0.03602371 & 7.84743665 & 0.0487 \\
\hline $\mathrm{F}$ & 0.0368 & 0.01359198 & 1 & 0.01359198 & 2.96088871 & 0.1604 \\
\hline G & -0.1287 & 0.1657404 & 1 & 0.1657404 & 36.1050351 & 0.0039 \\
\hline Residual & & 0.01836203 & 4 & 0.00459051 & & \\
\hline Lack of fit & & 0.01812003 & 3 & 0.00604001 & 24.9587134 & 0.1458 \\
\hline Pure error & & 0.000242 & 1 & 0.000242 & & \\
\hline Cor Total $^{\mathrm{c}}$ & & 0.43995883 & 11 & & & \\
\hline
\end{tabular}

${ }^{\mathrm{a}}$ In terms of coded factors. For the intercept, the estimated coefficient is $0.39 .{ }^{b}$ Degree of freedom. ${ }^{c}$ Sum of total squares corrected for the mean.

The significant factors (at $5 \%$ significance level) are shown in bold type.

variables $\mathrm{C}, \mathrm{D}$, and $\mathrm{F}$ were considered insignificant and were not included in the next step of the CCD experiments (see Table 4).

Figure 3 shows the time evolution of the $\mathrm{MB}$ adsorption signal for copolymer films of VBT: VPS ${ }_{1}$ and VBT: $\mathrm{VPS}_{4}$ at $2 \%$ concentration. It can clearly be seen that the time evolution of $1: 1$ is faster than $1: 4$, reaching a similar maximum absorption value at $60 \mathrm{sec}$ and $450 \mathrm{sec}$, respectively. Therefore, at the irradiation time used in the experiments $(60 \mathrm{sec})$ the signal intensity of the MB dye adsorbed on the crosslinked polymers is about $65 \%$ lower for 1:4 than $1: 1$, being the former less energy efficient. These results are consistent with the fact that decreasing the amount of the crosslinkable monomer, VBT, also slows down the curing process and consequently the amount of dye adsorbed after washing. For that reason, the comonomer ratio 1:4 was not included in the CCD model. On the other hand, as it was shown in a reported work [31], films made using coating rods no. 6 give rise to thicker films $(13.6 \mu \mathrm{m})$ that need longer irradiation times to crosslink and produce comparable signal intensities of the adsorbed dye. Therefore, the coating thickness was also excluded in the CCD model.

Finally, the inclusion of a duplicate as mentioned in the experimental section allowed the model fit determination. The "lack of fit $F$ value" of 24.96 suggests that it is not significant relative to the pure error: there is a $14.58 \%$ chance that a "Lack of Fit $F$-value" this large could occur due to experimental noise [30].

3.3. Optimization Step. CCD was used to study the correlations between the significant factors and to determine their 
TABLE 5: Central composite design matrix and the corresponding experimental and predicted responses for dye adsorption on crosslinked polymer process.

\begin{tabular}{lcccc}
\hline \multirow{2}{*}{ Run order } & \multirow{2}{*}{ pH } & Concentration & \multicolumn{2}{c}{$\begin{array}{c}\text { Absorbance } \\
\text { a }\end{array}$} \\
& & & 0.63 & 0.57 \\
\hline 1 & 9.0 & 6 & 0.60 & 0.58 \\
2 & 7.5 & 8 & 0.49 & 0.50 \\
3 & 7.5 & 4 & 0.41 & 0.41 \\
4 & 9.0 & 2 & 0.46 & 0.48 \\
5 & 10.5 & 4 & 0.48 & 0.50 \\
6 & 6.0 & 6 & 0.75 & 0.73 \\
7 & 10.5 & 8 & 0.57 & 0.57 \\
8 & 9.0 & 6 & 0.71 & 0.74 \\
9 & 9.0 & 10 & 0.63 & 0.64 \\
10 & 12.0 & 6 & &
\end{tabular}

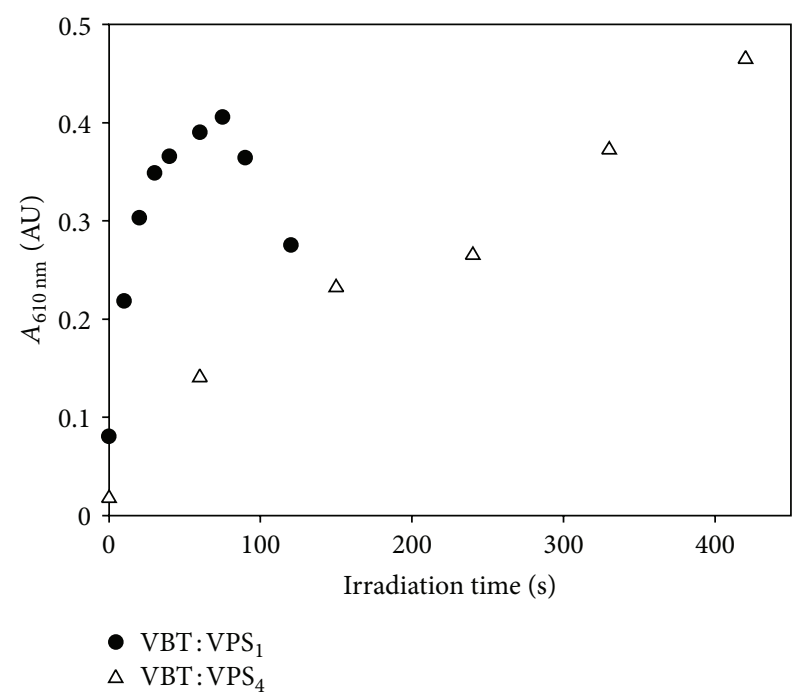

FIgURE 3: Time evolution of MB adsorption signal for the copolymers VBT: $\operatorname{VPS}_{1}(\bullet)$ and VBT: $\operatorname{VPS}_{4}(\triangle)$ at the same concentration (2\%).

optimal levels. The central composite design matrix of tested variables and the experimental results are represented in Table 5.

The competence of the model was checked using ANOVA, as shown in Table 6. The " $F$ value" of the model was 34.4 , and the $P$ value of "Prob $>F$ " was $<0.05$, suggesting that the model proposed for the raised CCD (two-factor interaction) was significant. Linear terms of $X_{1}, X_{2}$ and interaction term of $X_{1} X_{2}$ were significant for dye adsorption process.

From ANOVA, the experimental results of RSM fitted via the response surface regression procedure is a polynomial equation with the following expression:

$$
Y=\beta_{0}+\beta_{1} X_{1}+\beta_{2} X_{2}+\beta_{12} X_{1} X_{2}
$$

in which $Y$ is the predicted response, $X_{i}$ are the independent variables with $i=1$ and $2, \beta_{0}$ is the offset term, $\beta_{i}$ is the $i$ th linear coefficient, and $\beta_{12}$ is the $X_{1}$ and $X_{2}$ interaction coefficient.
The coefficient of determination $\left(R^{2}\right)$ was calculated as 0.9451 for dye adsortion according to (1), indicating a good agreement between the experimental and the predicted values. The pred- $R^{2}$ of 0.8627 was in reasonable agreement with adj- $R^{2}$ of 0.9176 . The value of "adequate precision," which measures the signal-to-noise ratio, resulted in a value of 16.5 suggesting an adequate signal [27]. The "lack of fit $F$ value" of 0.51 implied that the "lack of fit" was not significantly relative to the pure error. The model was found to be adequate for prediction within the range of variables employed.

The graphical representations of the regression model (see (1)) and their corresponding contour plot were obtained using Design-Expert software and are presented in Figure 4 for comonomer ratio $1: 1$. The surface response plot represents the effect of two independent numerical variables, that is, $\mathrm{pH}$ and polymer concentration. The shape of the corresponding contour plot indicates whether or not the mutual interaction between the independent variables is significant. As shown in Figure 4, the surface response of absorbance indicates the presence of two regions of maximum response, one at high concentration and $\mathrm{pH}$ and the other at low $\mathrm{pH}$. The optimum value found for the numerical variables for this copolymer composition using the CCD model equation is $9 \%$ for concentration and $10.7 \%$ for $\mathrm{pH}$.

A decrease in absorbance happens when the $\mathrm{pH}$ value is increased from 6 to 12 , for concentrations up to $6 \%$, giving rise to a relative maximum in the surface. The observed decrease of the absorbance at low concentration suggested that at high $\mathrm{pH}$ value the thymine moiety is present in the anionic form producing a strong reduction of the crosslinking process, as it was mentioned above.

At concentrations higher than $6 \%$ the tendency is inverse, so that the absorbance enlarges when $\mathrm{pH}$ varies from 6 to 12 , showing an absolute maximum at $10 \%$ concentration. Therefore, at higher concentrations that effect of $\mathrm{pH}$ is diminished, and the absorbance turns out to be in direct relation to the polymer concentration.

The nature of the contour plot indicates that the mutual interaction between the two independent variables $\left(X_{1}, X_{2}\right)$ was significant, which means that the effect of $\mathrm{pH}$ on the response was dependent on the level of concentration used, being negligible at concentrations larger than $6 \%$.

3.4. Validation of the RSM Model. The validation of the statistical model and the regression equation were conducted by taking into account the values of the variables corresponding to maximum response calculated from (1). Under these optimized conditions, the predicted response for dye adsortion was 0.82 , and the observed experimental value was $0.83 \pm 0.03$, an average of triplicate measurements. These results confirmed the validity of the model, and the experimental values were regarded to be quite close to the predicted values.

\section{Conclusions}

Results suggested that statistical strategy is an effective and important tool for the optimization of experimental 
TABLE 6: ANOVA for RSM two factor interaction model.

\begin{tabular}{lccccc}
\hline Source & Coefficient estimate $^{\mathrm{a}}$ & Sum of squares & $\mathrm{df}^{\mathrm{b}}$ & Mean square & $\begin{array}{c}F \text { value } \\
\text { Prob }>F\end{array}$ \\
\hline Model & & 0.10592423 & 3 & 0.03530808 & 34.3997072 \\
$X_{1}$-pH & -0.069 & 0.01380408 & 1 & 0.01380408 & 13.4489461 \\
$X_{2}$-Conc. & -0.095 & 0.08377837 & 1 & 0.08377837 & 81.6230066 \\
$X_{1} X_{2}$ & 0.015 & 0.00834178 & 1 & 0.00834178 & 8.12716909 \\
Residual & & 0.00615844 & 6 & 0.00102641 & 0.0105 \\
$\quad$ Lack of Fit & & 0.00441794 & 5 & 0.00088359 & 0.50766308 \\
$\quad$ Pure Error & & 0.0017405 & 1 & 0.0017405 & 34.3997072 \\
Cor Total & & 0.11208267 & 9 & & 0.7806 \\
\hline
\end{tabular}

${ }^{\mathrm{a}}$ In terms of actual factors. For the intercept, the coefficient estimate is $0.9406 .{ }^{\mathrm{b}}$ Degree of freedom. ${ }^{\mathrm{c}}$ Sum of total squares corrected for the mean.
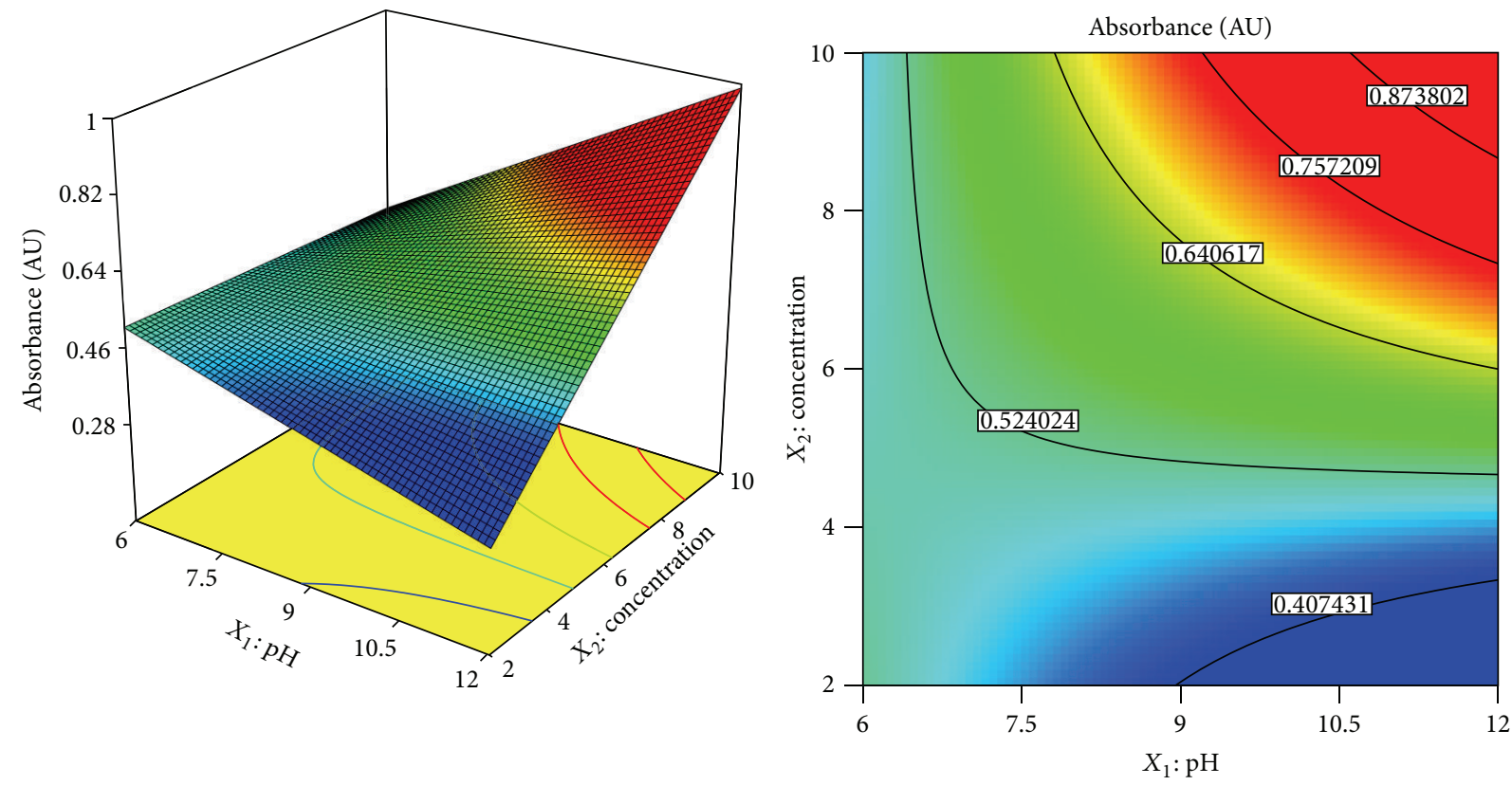

FIGURE 4: Three-dimensional response surface plots and two-dimensional contour plots for dye adsorption process on photocrosslinking polymer showing the interactions between $\mathrm{pH}$ and concentration variables for VBT: $\mathrm{VPS}_{1}$.

parameters involved in dye adsorption on crosslinked polymer processes. In addition, to the best of our knowledge, this was the first report applying statistical experimental designs to optimize the crosslinking of thymine-based polymers. The PBD results assigned a maximum absorption signal of 0.67 , while following the CCD method predictions, a response of 0.83 was obtained. The $\mathrm{pH}$ effect was relevant for low concentrations (less than 6\%) but, as it was shown, not important for higher concentrations. Optimal conditions obtained in this experiment lead to a solid foundation for further use of this methodology in the production of potential photoresistors.

\section{Conflict of Interests}

The authors do not have any direct financial relation with any commercial identity mentioned in the paper and have declared that there is no conflict of interests.

\section{Acknowledgments}

Débora M. Martino, Carlos E. Boschetti, and Santiago A. Bortolato are members of the Research Council of CONICET. The authors would like to thank Universidad Nacional del Litoral (CAI+D Tipo II PI 11-57), CONICET (PIP 112-20080101079 and D-1280/2011), and the NSF OISE (Grant no. 1031394) for the financial support.

\section{References}

[1] H. J. Levinson, Principles of Lithography, SPIE The International Society for Optical Engineering, 2001.

[2] K. Takemoto, "Functional monomers and polymers containing nucleic acid bases," Journal of Polymer Science: Polymer Symposia, vol. 55, pp. 105-125, 1976.

[3] Y. Inaki, "Thymine polymers as high resolution photoresists and reversible photo-recording materials," Polymer News, vol. 17, pp. 367-371, 1992. 
[4] G. M. Blackburn and R. J. H. Davies, "The structure of thymine photo-dimer," Journal of the Chemical Society C, vol. 23, pp. 2239-2244, 1966.

[5] A. A. Lamola and J. P. Mittal, "Solution photochemistry of thymine and uracil," Science, vol. 154, no. 3756, pp. 1560-1561, 1966.

[6] C. M. Cheng, M. J. Egbe, M. J. Grasshoff et al., "Synthesis of 1-(vinylbenzyl)thymine, a novel, versatile multi-functional monomer ," Journal of Polymer Science A, vol. 33, pp. 2515-2519, 1995.

[7] J. M. Grasshoff, L. D. Taylor, and J. C. Warner, "Copolymeric mordants and photographic products and processes containing same," U.S. Patent 5,395,731, March 1995.

[8] J. M. Grasshoff, L. D. Taylor, and J. C. Warner, "Vinylbenzyl thymine monomers," U.S. Patent 5,455,349, October 1995.

[9] C. Kiarie, J. Bianchini, S. Trakhtenberg, and J. C. Warner, "Methylene blue adsorption on thymine based polyvinylphenylsulfonate films," Journal of Macromolecular Science A, vol. 42, no. 11, pp. 1489-1496, 2005.

[10] J. R. Bianchini, K. Saito, T. B. Balin, V. Dua, and J. C. Warner, "Thymine-based, water-soluble phototerpolymers: their preparation and synthesis," Journal of Polymer Science A, vol. 45, no. 7, pp. 1296-1303, 2007.

[11] A. S. Cannon, J. Raudys, A. Undurti, and J. C. Warner, "Photoreactive Polymers and Devices for use in Hair Treatments," PCT Int. Appl., WO 2004058187, p. 23, 2004.

[12] J. M. Grasshoff, L. D. Taylor, and J. C. Warner, "Method of imaging using a polymeric photoresist having pendant vinylbenzyl thymine groups," U.S. Patent 5,616,451, April 1997.

[13] J. M. Grasshoff, L. D. Taylor, and J. C. Warner, "Copolymers having pendant functional thymine groups," U.S. Patent 5,708,106, January 1998.

[14] L. Lloyd-Kindstrand and J. C. Warner, "Thymine-containing styrene polymers as environmentally benign photoresists," in Biopolymers, S. Matsumura and A. Steinbüchel, Eds., vol. 9, pp. 165-174, John Wiley \& Sons, Weinheim, Germany, 2003.

[15] S. Trakhtenberg, Y. Hangun-Balkir, J. C. Warner et al., "Photocross-linked immobilization of polyelectrolytes for enzymatic construction of conductive nanocomposites," Journal of the American Chemical Society, vol. 127, no. 25, pp. 9100-9104, 2005.

[16] K. Saito, L. R. Ingalls, J. Lee, and J. C. Warner, "Corebound polymeric micellar system based on photocrosslinking of thymine," Chemical Communications, no. 24, pp. 2503-2505, 2007.

[17] K. Saito and J. C. Warner, "Core-shell thymine containing polymeric micelle system: study of controlled release of riboflavin," Green Chemistry Letters and Reviews, vol. 2, no. 2, pp. 71-76, 2009.

[18] G. Kaur, S. L. Y. Chang, T. D. M. Bell, M. T. W. Hearn, and K. J. Saito, "Bioinspired core-crosslinked micelles from thyminefunctionalized amphiphilic block copolymers: hydrogen bonding and photo-crosslinking study," Journal of Polymer Science A, vol. 49, pp. 4121-4128, 2011.

[19] S. A. Bortolato, A. L. Barbarini, R. M. Benitez, D. A. Estenoz, and D. M. Martino, "Photo-induced curing of thymine-based bioinspired polymers. A chemometric analysis,"Latin American Applied Research. In press.

[20] S. Trakhtenberg, J. C. Warner, R. Nagarajan, F. F. Bruno, L. A. Samuelson, and J. Kumar, "Spectroscopic and microscopic analysis of photo-cross-linked vinylbenzylthymine copolymers for photoresist applications," Chemistry of Materials, vol. 18, no. 12, pp. 2873-2881, 2006.
[21] M. J. Bowden, "A perspective on resist materials for fineline lithography," in Materials For Microlithography. RadiationSensitive Polymers, L. F. Thompson, C. G. Willson, and J. M. J. Frechet, Eds., ACS, Washington, DC, USA, 1984.

[22] M. A. Morsy, A. M. Ai-Somali, and A. Suwaiyan, "Fluorescence of thymine tautomers at room temperature in aqueous solutions," Journal of Physical Chemistry B, vol. 103, no. 50, pp. 11205-11210, 1999.

[23] N. J. Miller and N. C. Miller, Statistics and Chemometrics For Analytical Chemistry, chapter 7, Prentice Hall, 5th edition, 2005.

[24] D. B. Hibbert, "Experimental design in chromatography: a tutorial review," Journal of Chromatography A, vol. 910, pp. 213, 2012.

[25] P. Wang, Z. Wang, and Z. Wu, "Insights into the effect of preparation variables on morphology and performance of polyacrylonitrile membranes using Plackett-Burman design experiments," Chemical Engineering Journal, vol. 193, pp. 50-58, 2012.

[26] J. Zhou, X. Yu, C. Ding et al., “Optimization of phenol degradation by Candida tropicalis Z-04 using Plackett-Burman design and response surface methodology," Journal of Environmental Sciences, vol. 23, no. 1, pp. 22-30, 2011.

[27] Design Expert Version 7, Stat-Ease Inc., Minneapolis, Minn, USA.

[28] D. M. MacLeod, "Wire-Wound rod coating," in Coating Technology Handbook, D. Satas, Ed., Marcel Dekker, New York, NY, USA, 1991.

[29] R. L. Plackett and J. P. Burman, "The design of optimum multifactorial experiments," Biometrika, vol. 33, pp. 305-325, 1946.

[30] W. P. Gardiner, Statistical Analysis Methods For Chemists. A Software-Based Approach, The Royal Society of Chemistry, London, UK, 1997.

[31] A. L. Barbarini, D. L. Reyna, and D. M. Martino, "The effect of light intensity, film thickness, and monomer composition in styrene-based bioinspired polymers," Green Chemistry Letters and Reviews, vol. 3, no. 3, pp. 231-237, 2010.

[32] A. L. Barbarini, D. M. Martino, and D. A. Estenoz, "Synthesis, characterization and curing of bioinspired polymers based on vinyl benzyl thymine and triethyl ammonium chloride," Macromolecular Reaction Engineering, vol. 4, pp. 453-460, 2010. 

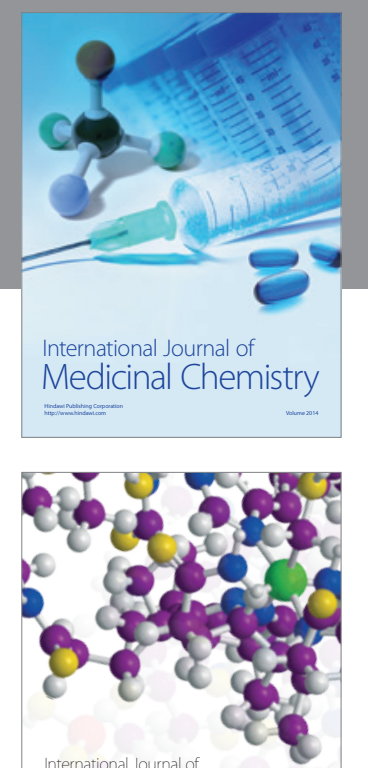

\section{Carbohydrate} Chemistry

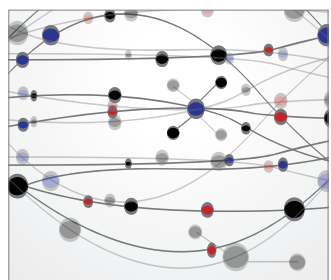

The Scientific World Journal
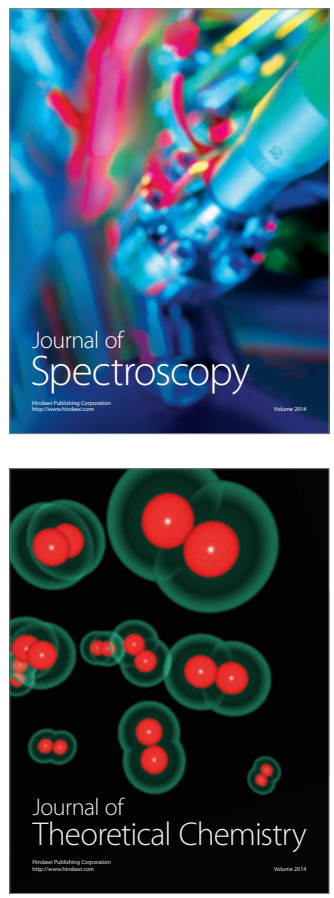
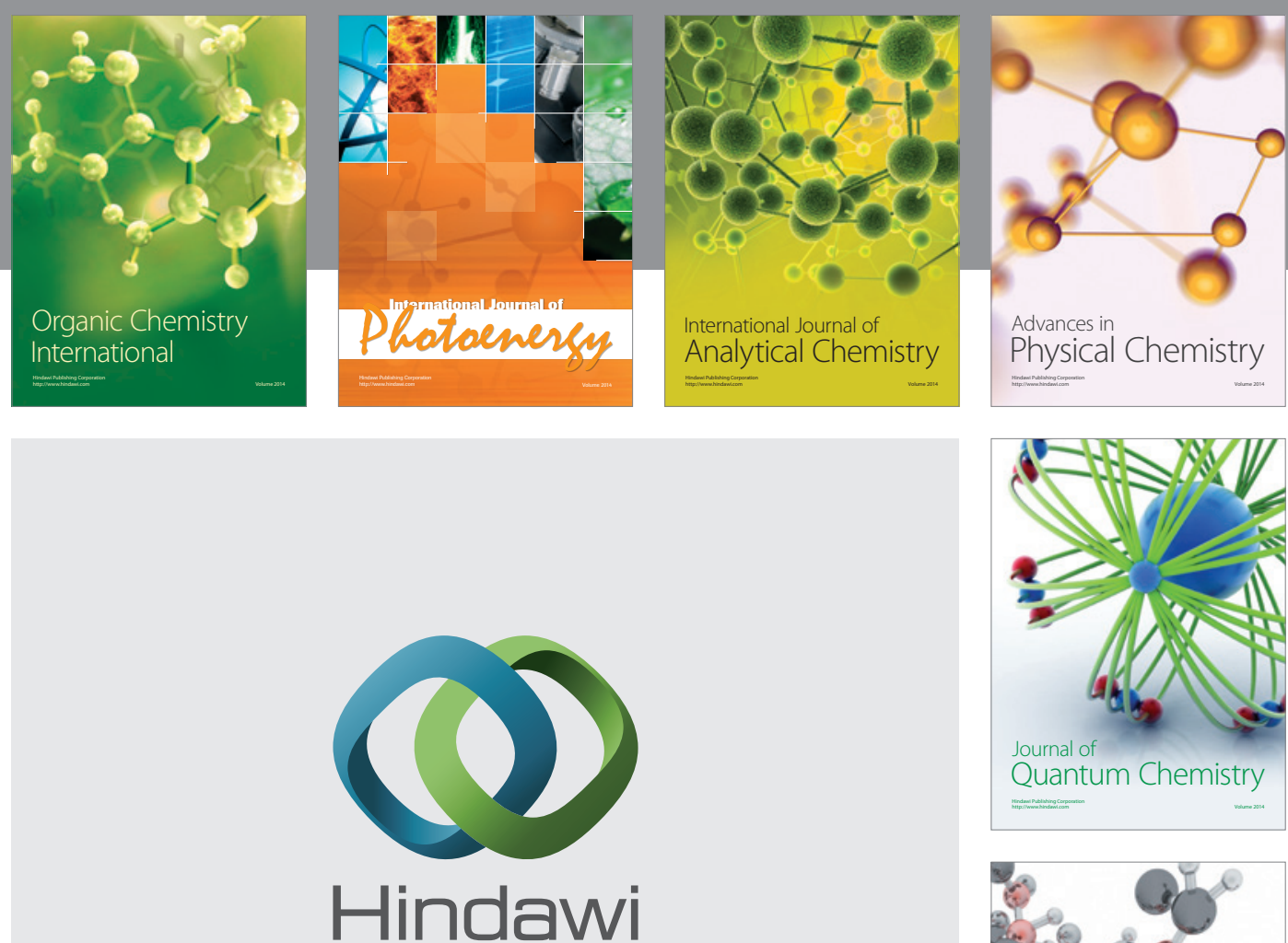

Submit your manuscripts at

http://www.hindawi.com

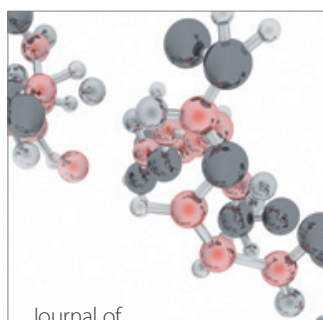

Analytical Methods

in Chemistry

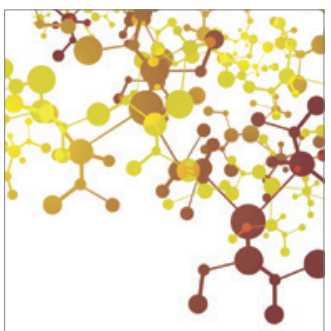

Journal of

Applied Chemistry

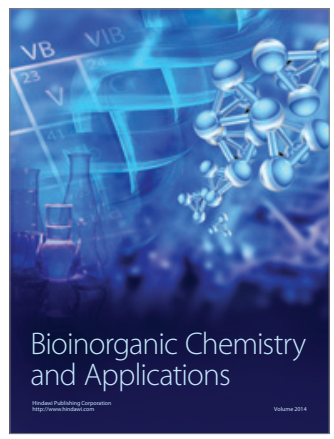

Inorganic Chemistry
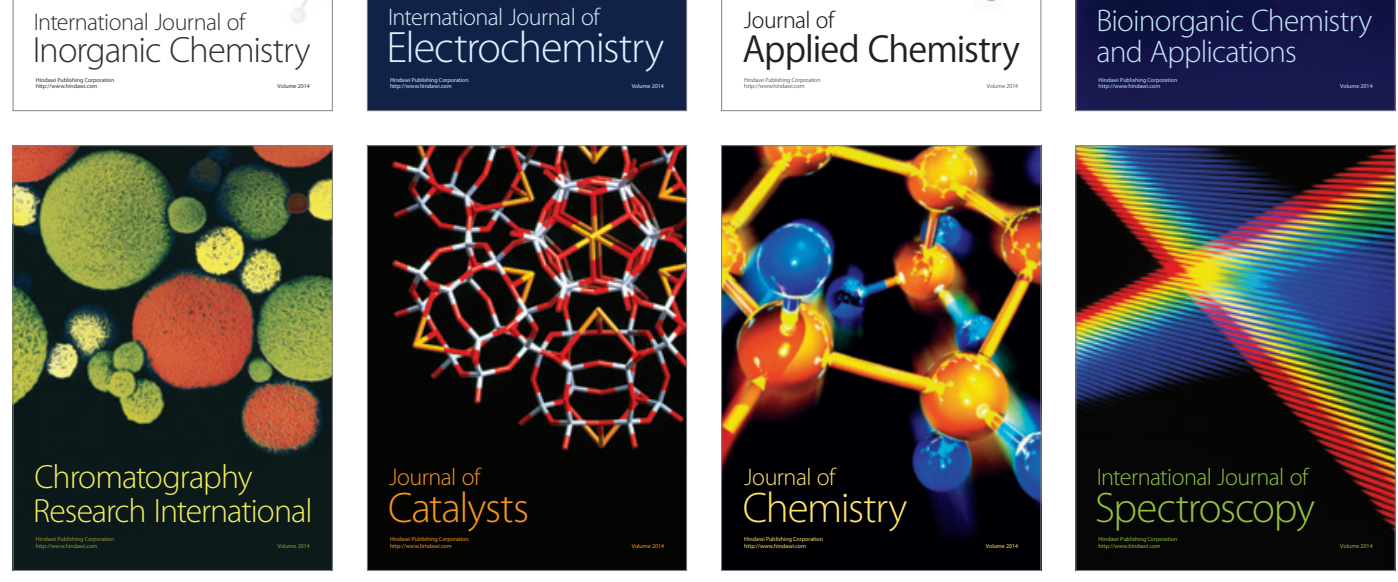